\title{
Local Nusselt number enhancements in liquid-liquid Taylor flows
}

\author{
Marc Mac Giolla Eain ${ }^{\mathrm{a}, *}$, Vanessa Egan ${ }^{\mathrm{a}}$, Jeff Punch ${ }^{\mathrm{b}}$ \\ a Stokes Institute, Mechanical Aeronautical \& Biomedical Engineering, University of Limerick, Limerick, Ireland \\ ${ }^{\mathrm{b}}$ CTVR, Stokes Institute, University of Limerick, Limerick, Ireland
}

\section{A R T I C L E I N F O}

\section{Article history:}

Received 2 April 2014

Received in revised form 28 August 2014

Accepted 3 September 2014

Available online 28 September 2014

\section{Keywords:}

Heat transfer

Slug flow

Liquid-liquid

Slug length

Film thickness

Minichannels

\begin{abstract}
A B S T R A C T
Thermal management has emerged as a critical requirement to ensure the performance and reliability of electronic devices and systems. System level heat fluxes are approaching the limits of conventional forced air cooling, and there is a need to develop alternative cooling techniques for devices such as processors, power amplifiers and laser arrays. This paper examines the potential heat transfer enhancements of a two phase liquid-liquid Taylor flow regime. The primary focus of the work was to examine the influence of slug length and carrier phase variations on the local Nusselt numbers. An experimental facility was designed and commissioned to subject the flow to a constant heat flux boundary condition, a boundary condition commonly encountered in thermal management applications. Local temperature measurements were acquired using a high resolution infrared thermography system. Experiments were carried out over slug length, Capillary and Prandtl numbers that spanned several orders of magnitude in a minichannel geometry. Reductions in carrier slug length and increases in dispersed slug length were found to augment the heat transfer rates, with the greatest enhancements observed in flows with carrier slug lengths approaching the channel diameter. The thickness of the liquid film separating the dispersed slugs from the heated capillary walls was found to play a significant role in the removal of heat, with increases in film thickness resulting in a reduction in the heat transfer rates. Based on the characteristics identified, a novel correlation is proposed to model the flow in the thermally developing and fully-developed regions.
\end{abstract}

(c) 2014 Elsevier Ltd. All rights reserved.

\section{Introduction}

Contemporary electronic devices and systems permeate virtually every aspect of our lives. These devices and systems generate large heat fluxes at component level, which is the result of two main trends: the escalation of power dissipation from components; and the reduction in available surface area from which to transfer heat. Today's microprocessors generate heat fluxes of order $100 \mathrm{~W} / \mathrm{cm}^{2}$, while in high end microprocessors this value is closer to $300 \mathrm{~W} / \mathrm{cm}^{2}$ [1]. Consequently, a significant body of research exists focused solely on the development of high heat flux removal technologies. The primary objective of these technologies is to dissipate these high heat loads while maintaining components within safe operating temperature limits. For decades this has been accomplished using forced air convection cooling, whose benefits include simplicity, low cost, ease of maintenance and high reliability $[2,3]$. However, escalating power dissipation levels necessitate higher air flow rates and hence, larger and more powerful fans,

\footnotetext{
* Corresponding author. Tel.: +353 61233619; fax: +353 61202393

E-mail address: marc.macgiollaeain@ul.ie (M. Mac Giolla Eain).
}

thereby exacerbating the problems associated with profile, noise and vibration control. Hence, conventional forced air convection cooling techniques are no longer sufficient, thus driving the need for alternative cooling modes to the fore. At present, liquid cooling is seen as the prevailing alternative. Liquid cooling yields significantly enhanced heat transfer coefficients compared to air based counterparts, thus allowing further advances in processer performance and miniaturisation. Examples of liquid cooling include: cold plates, [4], impinging jets, [5], spray cooling, [6], microgap cooling, [7], and microchannels, [8], with microchannels seen as the pre-eminent solution.

The use of microchannels for high power density cooling has been widely studied since the pioneering work of Tuckerman and Pease [9]. Theoretically, a microchannel flow possesses high surface-area to volume ratios, thereby generating high heat transfer coefficients. However, a result of the reduced channel dimensions is a laminar flow regime, [10], hence Nusselt numbers do not exceed those of equivalent macroscale systems. Accordingly, microchannel research is now focused towards methods of enhancing the heat transfer rates above macroscale systems. Potential enhancement methods include the addition of: specifi- 


\section{Nomenclature}

$\mathrm{Ca} \quad$ capillary number $(\mu U / \sigma)(-)$

$c_{p} \quad$ specific heat capacity $(\mathrm{kJ} / \mathrm{kg} \mathrm{K})$

$D \quad$ diameter (m)

$h \quad$ convective heat transfer coefficient $\left(\mathrm{W} / \mathrm{m}^{2} \mathrm{~K}\right)$

$k \quad$ thermal conductivity $(\mathrm{W} / \mathrm{m} \mathrm{K})$

$L \quad$ length (m)

$L^{*} \quad$ dimensionless length $(L / D)(-)$

$\mathrm{Nu} \quad$ Nusselt number $(h D / k)(-)$

Pe Peclet number $(U D / \alpha)(-)$

Pr Prandtl number $\left(\mu c_{p} / k\right)(-)$

$Q \quad$ volumetric flow rate $\left(\mathrm{m}^{3} / \mathrm{s}\right)$

$q^{\prime \prime} \quad$ heat flux $\left(\mathrm{W} / \mathrm{m}^{2}\right)$

$R \quad$ radius $(\mathrm{m})$

Re Reynolds number $(\rho U D / \mu)(-)$

$T$ temperature $\left({ }^{\circ} \mathrm{C}\right)$

$U \quad$ bulk mean velocity $(\mathrm{m} / \mathrm{s})$

We Weber number $\left(\rho U^{2} D / \sigma\right)(-)$

$x \quad$ axial position $(\mathrm{m})$

$x^{*} \quad$ inverse Graetz number $(x / D R e P r)(-)$

Greek Symbols

$\alpha \quad$ thermal diffusivity $\left(\mathrm{m}^{2} / \mathrm{s}\right)$ $\delta \quad$ film thickness (m)

$\varepsilon \quad$ void fraction (-)

$\varepsilon_{m} \quad$ modified void fraction (-)

$\mu \quad$ dynamic viscosity $(\mathrm{kg} / \mathrm{m} \mathrm{s})$

$\rho \quad$ density $\left(\mathrm{kg} / \mathrm{m}^{3}\right)$

$\sigma \quad$ interfacial tension $(\mathrm{N} / \mathrm{m})$

Subscripts

BM bulk mean

C continuous oil phase

$D$ dispersed water phase

Dev developed

Ent entrance

in inlet

Plug plug flow

Pois Poiseuille flow

$S \quad$ slug flow

$T$ total

W wall

$x \quad$ local axial position cally engineered nano-particles to enhance the thermal conductivity of the fluid [11], microencapsulated phase change materials (MPCM) [12], vortex promoters to the channel surface [13] and multiphase flows [14]. Research, by authors such as Betz and Attinger [15] and Che et al. [16], has shown that multiphase flows offer the best potential for increased heat transfer rates. Thermally, multiphase flows have been studied from both boiling and nonboiling perspectives. In a boiling multiphase flow regime, the surface temperature exceeds the saturation temperature of the coolant. This results in a change in phase within the heat exchanger, which generates very high local heat transfer coefficients. However, boiling heat transfer can be difficult to control and quantify; and it requires sealed vessels for containment. Nonetheless, a considerable body of research exists in this area [17-19]. Alternatively, the use of non-boiling multiphase flows to remove high heat loads has received considerably less attention in the literature and is the focus of the present study. Non-boiling multiphase flows are generated when two immiscible phase are pumped into a channel at a variety of flow rates. The generated flow regimes are the result of surface and body force interactions and include: churn, annular, wavy, slug and stratified [20]. At the micro-scale, however, surface forces dominate over the gravitational, resulting in the slug or Taylor flow regime being the most commonly encountered. A Taylor flow regime consists of a series of slugs dispersed at regular inter- vals, suspended in a continuous carrier phase, which also forms slugs and is illustrated in Fig. 1. The dispersed slugs occupy the majority of the capillary cross-section, with only a thin axisymmetric film of the carrier phase separating the dispersed slugs from the capillary walls.

Some of the earliest works examining the heat transfer rates in non-boiling two-phase slug flows were those of Prothero and Burton [21], who noted that segmenting a continuous stream of liquid with gaseous bubbles was almost twice as effective in transferring heat as Poiseuille flow. Examining the phenomenon, Oliver and Young [22] noted that two distinct mechanisms were responsible for the enhanced heat transfer rates generated by such a flow regime: the increased velocity of the liquid phase, resulting from the addition of the gaseous phase, and an internal circulation within the liquid phase. Analysing the problem analytically, Muzychka et al. [23] came to similar conclusions, that the improved thermal performance is attributable to the modified velocity profile in the liquid slug and the internal circulation. A number of studies have examined the problem experimentally, [15,24,25], and have reported Nusselt number enhancements up to $600 \%$ over conventional Poiseuille flows, [26]. In the majority of these studies, the flow regime consisted of gaseous bubbles dispersed in a continuous liquid medium. However, the thermophysical properties of gases render them less attractive as coolants. Their comparatively

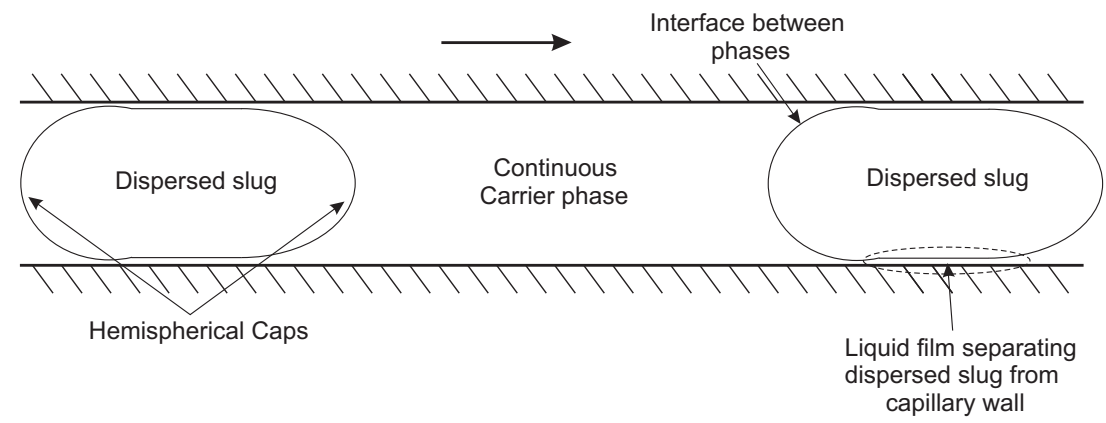

Fig. 1. Taylor flow regime consisting of slugs dispersed at regular intervals in a continuous carrier phase. 
lower density, $\left(\rho \approx 1.2 \mathrm{~kg} / \mathrm{m}^{3}\right)$, and specific heat capacities, $\left(c_{p}-\right.$ $\approx 1 \mathrm{~kJ} / \mathrm{kg} \mathrm{K}$ ), curtail their efficiency in heat removal by convection. Water is a common liquid coolant and possess thermophysical properties much more conducive to cooling by convection, with higher densities, $\left(\rho \approx 900 \mathrm{~kg} / \mathrm{m}^{3}\right)$, and specific heat capacities, $\left(c_{p}-\right.$ $\approx 4 \mathrm{~kJ} / \mathrm{kg} \mathrm{K}$ ), providing a greater capacity to transfer heat. Therefore, replacing the gaseous phase with an immiscible liquid phase should result in improved heat transfer rates over liquidgas flows. To date, only one study has examined the potential of segmented liquid-liquid flows in the removal of high heat loads, Asthana et al. [1]. While the authors reported some interesting findings, a number of key questions were left unanswered, specifically: the effects of slug length on Nusselt number and Prandtl number effects on the heat transfer rates. This paper addresses this deficit in the literature and answers these open questions. An experimental facility was built to examine the phenomenon in tube flow when subjected to a constant wall heat flux boundary condition. A segmented liquid-liquid slug flow regime was generated consisting of aqueous slugs dispersed in a continuous carrier phase. The carrier phase was varied, while the dispersed phase remained constant throughout. The variations in thermophysical properties of the carrier phases resulted in measurements over the following ranges in parameters: $0.001<C a<0.119$, $23.6<\operatorname{Pr}<265.4$. Dimensionless heat transfer rates, expressed in terms of the Nusselt number, were inferred from the experimental measurements; and are presented with inverse Graetz numbers that span three orders of magnitude.

\section{Theory}

This section presents the relevant analytical expressions required to thermally characterise single and two phase flows in both the developing and fully-developed regions for internal channel flows. The particular problem being examined in this study addresses the development of the thermal boundary layer in a hydrodynamically fully-developed laminar flow that is subject to a constant wall heat flux boundary condition. Dimensionless heat transfer rates for such flows are characterised by local Nusselt numbers, as defined by Eq. (1):

$N u_{x}=\frac{h_{x} D}{k}=\frac{q^{\prime \prime} D}{k\left(T_{w, x}-T_{B m}\right)}$

In addition to this, the dimensionless position downstream from the entrance to the heated section is characterised by the inverse Graetz number. This parameter is referred to as $x^{*}$ throughout and is defined by Eq. (2):

$x^{*}=\frac{x}{D R e P r}=\frac{x}{D P e}$

For fully-developed laminar flow, the velocity profile at any cross-section is known; hence the energy conservation equation can be solved to provide an exact solution of the temperature field. A solution of this type was initially presented by Graetz $[27,28]$. This allowed later for the development of simplified piecewise analytical expressions defining the variation in the local Nusselt number with dimensionless position [29]. Solutions of this nature are separated into two distinct regions where, in the first region, an expression is defined for the entrance region while, in the second region, the flow is fully-developed thermally and the Nusselt number is constant. Using the addition of asymptotes approach, Muzychka and Yovanovich [30] combined such expressions and arrived at the expression presented in Eq. (3). This expression defines the variation in local Nusselt number with dimensionless position when the flow is subject to a constant wall heat flux boundary condition and the fluid Prandtl number, $P r$, is greater than unity:
$N u_{x, \text { Pois }}=\left[\left(\frac{1.302}{\chi^{* 1 / 3}}\right)^{5}+(4.36)^{5}\right]^{1 / 5}$

Also of interest in the present study is the theoretical solution obtained as the $\operatorname{Pr}$ limit approaches zero. Such a solution is known as the plug flow limit and occurs when either an inviscid fluid or solid rod passes through a channel. Hence, the fluid flows as a solid plug with a uniform velocity profile across the channel cross-section. Muzychka et al. [23] developed an analytical expression, presented in Eq. (4), that describes the variation in local Nusselt number with dimensionless position when a constant wall heat flux boundary condition is applied to such a flow species:

$N u_{x, \text { Plug }}=\left[\left(\frac{0.886}{x^{* 1 / 2}}\right)^{2}+(7.96)^{2}\right]^{1 / 2}$

In subsequent sections, the single phase heat transfer prediction offered by Eq. (3) will be used to validate the experimental test facility by providing a comparison with single phase benchmark tests. Also, the models presented in Eqs. (3) and (4) will be used as an indicator to gauge the level of enhancement offered by liquid-liquid slug flows.

\section{Experimentation}

In order to thermally characterise liquid-liquid slug flow regimes, a custom experimental facility was designed and constructed. A description of the bulk heat transfer setup, infrared (IR) system, IR image analysis, system calibration and uncertainty analysis are presented in this section.

\subsection{Bulk heat transfer setup}

Fig. 2 shows a schematic of the experimental facility used. The setup was designed and constructed such that it: (1) could produce a continuous stream of liquid-liquid slugs whose length could be accurately controlled and measured; (2) contained a heated test section that could subject the flow to a constant wall heat flux boundary condition; and (3) could obtain high resolution local measurements of the heated section surface temperature. Experiments were carried out using a selection of different carrier fluids, while water was used as the discontinuous phase throughout. Three different carrier fluids were examined in order to provide a wide range in physical properties and hence Capillary and Prandtl numbers. The three different carrier fluids examined were: Pd5, Dodecane and AR20 silicone oils. The relevant thermophysical properties of the different media are presented in Table 1, while the resultant dimensionless parameters of the experiments are presented in Table 2.

Two precision Harvard PhD 2000 programmable syringe pumps were used to set the volumetric flow rates. Separate syringe pumps allowed the relative flow rates, and hence slug lengths, to be varied over a wide range. The liquid phases were delivered by $100 \mathrm{~mL}$ capacity Hamilton 1100TLL gas tight glass syringes. Glass syringes were used as they deliver steadier flow rates than those attainable from plastic syringes. The flows then merged inside either a segmenter or T-junction to create well-ordered streams of aqueous droplets separated from one another by oil slugs. Segmenters work by periodically creating and rupturing a liquid bridge between two opposing capillary tips and have been used by the authors in previous works examining the hydrodynamics of liquid-liquid slug flows [31,32]. Segmenters require the reservoir to be filled with a density matched oil to ensure that a buoyancy free environment exists for axis-symmetric liquid bridging. Consequently, only the Pd5/water slug flows were generated using segmenters. For the 


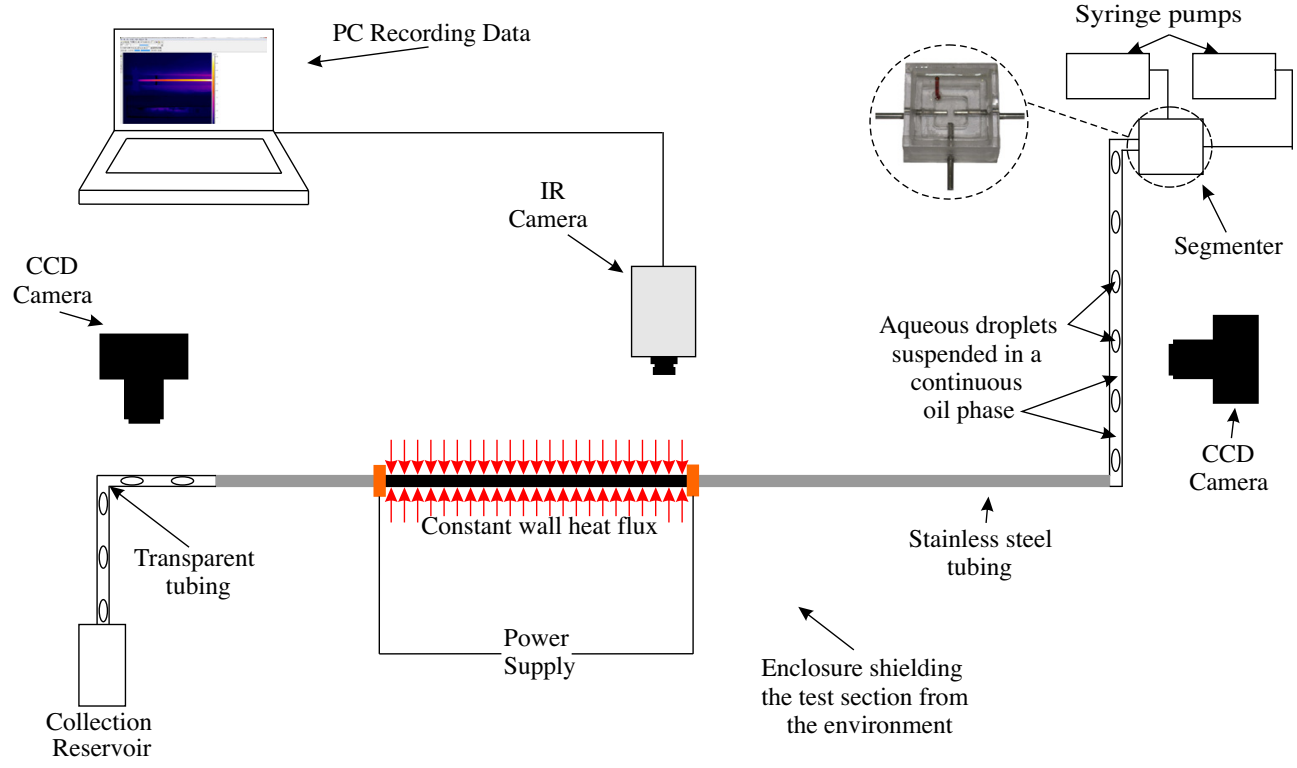

Fig. 2. Schematic of the experimental test facility.

Table 1

Thermophysical properties of the relevant fluids examined in this work.

\begin{tabular}{|c|c|c|c|c|c|}
\hline Fluid & Density $\left(\mathrm{kg} / \mathrm{m}^{3}\right)$ & Viscosity ( $\mathrm{kg} / \mathrm{m} \mathrm{s})$ & Interfacial tension $(\mathrm{N} / \mathrm{m})$ & Specific heat capacity (kJ/kg K) & Thermal conductivity $(\mathrm{W} / \mathrm{m} \mathrm{K})$ \\
\hline Pd5 & 911.8 & 0.00358 & 0.0397 & 1.68 & 0.11 \\
\hline Dodecane & 754.3 & 0.00139 & 0.0520 & 2.21 & 0.13 \\
\hline AR20 & 1142.2 & 0.02091 & 0.0302 & 1.65 & 0.13 \\
\hline Water & 997.1 & 0.00091 & - & 4.07 & 0.61 \\
\hline
\end{tabular}

Table 2

Range of parameters considered in this study.

\begin{tabular}{lll}
\hline Parameter & Minimum & Maximum \\
\hline$L_{C}^{*}$ & 0.2 & 22.9 \\
$L_{D}^{*}$ & 1.0 & 8.2 \\
$x^{*}$ & $8.1 \times 10^{-5}$ & $9.2 \times 10^{-2}$ \\
$\varepsilon$ & 0.04 & 0.75 \\
$U_{m}(\mathrm{~m} / \mathrm{s})$ & 0.03 & 0.13 \\
$\operatorname{Re}$ & 2.3 & 92.1 \\
$C a$ & 0.001 & 0.120 \\
$\operatorname{Pr}$ & 23.6 & 265.4 \\
\hline
\end{tabular}

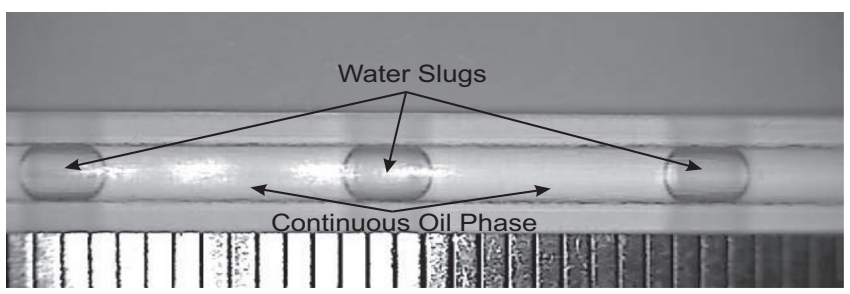

Fig. 3. Image of liquid-liquid Taylor flow used to determine aqueous droplet and oil slug lengths.

other oil/water combinations examined in this study, T-junctions were used, where the formation of the aqueous droplets is driven by the shear force exerted by the carrier phase.

Once generated, the slugs proceeded to flow through a transparent capillary of $1.5 \mathrm{~mm}$ internal diameter. The transparent nature of the capillary allowed visualisation of the flow to ensure that a stable and consistent slug train existed and that no coalescence of slugs had occurred. A series of images, such as that presented in
Fig. 3, were recorded at this location and analysed using a custom code developed in Matlab (version 2010a) to extract the average aqueous and oil slug lengths. The maximum variation in slug length was found to be less than $10 \%$.

The flow than preceded to the heated test section which consisted of a $1 \mathrm{~m}$ length of a $1.5 \mathrm{~mm}$ internal bore stainless steel tubing. However, only a short length, $0.3 \mathrm{~m}$, was heated during experimentation. Prior to reaching the heated section, the flow passed through a $0.4 \mathrm{~m}$ unheated entry length, to ensure the full hydrodynamic development of the flow. To minimise axial conduction losses and the temperature gradient through the wall, the tubing used had a wall thickness of $0.25 \mathrm{~mm}$. A constant wall heat flux boundary condition was achieved by Joule heating using a high current DC power supply. Electrical connections to the tube were made using custom made sharp edged copper ring contacts, thus ensuring the thermal entrance point could be clearly identified. Additionally, the use of copper as the material for the electrical connections ensured minimal internal heat generation, and their sharp edge connections minimised conductive heat loss. The inside of the stainless steel tube was coated with a thin layer, 5-15 $\mu \mathrm{m}$ thick, of polyurethane, thus providing a hydrophobic boundary condition. This ensured that the thin liquid film that separates the aqueous slugs from the capillary wall did not breakdown, thus maintaining the well-ordered slug trains.

\subsection{IR System}

External surface temperature measurements of the heated section were obtained using a high resolution IR thermography system. This consisted of a FLIR systems ThermaCam Merlin series IR camera. Such measurements required the exterior surface of the stainless steel test section to be sprayed matt black, to enhance 
surface emissivity. The emissivity of the surface was determined prior to testing by simultaneously comparing IR thermography measurements with equivalent measurements from four K-type thermocouples mounted on the tube surface just outside the field of view of the camera. To reduce the uncertainty in the temperature measurements, the thermocouples were calibrated prior to testing using a Lauda E100 RE1104 calibration bath. A temperature range of $10-70{ }^{\circ} \mathrm{C}$ was used for calibration. This reduced the uncertainty in thermocouple temperature measurement from the standard tolerance of $+2.2{ }^{\circ} \mathrm{C}$ to $+0.1^{\circ} \mathrm{C}$ as indicated by [33]. The emissivity of the surface was calculated by pumping single phase liquid through the tube at three known temperatures. This was done at sufficiently high flow rates to ensure that the temperature variance, due to natural convection losses, between the thermocouples was no greater than $0.1 \mathrm{~K}$. IR and thermocouple measurements were compared, and the test surface emissivity was calculated to be 0.96 , which would be a typical value of a matt black surface. During experimentation, the field-of-view of the IR camera extended over approximately $110 \mathrm{~mm}$ of the heated test section. All local temperature measurements were obtained within this region. The heated test section was placed within a custom enclosure to shield it from its environment, thereby minimising the effects of ambient convection currents within the laboratory and long wavelength radiation from high temperature surrounding bodies such as light fixtures or monitors. Additionally, during testing, both the IR camera and thermocouples were used to measure the surface temperature of the tube, thus allowing a continuous calibration check of the thermal imaging setup in situ.

For each test, images were recorded at a frequency of $1 \mathrm{~Hz}$ for a period of up to $10 \mathrm{~min}$, depending on the flow rates. While steady state was typically achieved within a 1 min period, such extended recording times were necessary due to the unsteady nature of the heat transfer processes under examination resulting from the periodic passing of aqueous and oil slugs.

\subsection{IR image analysis}

Once the series of IR images were recorded, it was necessary to extract the relevant wall temperature data. A custom code was developed in Matlab (version 2010a) to extract the transient temperature profile along the tube surface. Fig. 4 illustrates the procedure followed by this code. Fig. 4(a) shows an image of the test section prior to heating and incorporates a ruler to scale the images. Fig. 4(b) shows a region of interest being selected, as highlighted by the dashed line. Once selected, the code uses an edge detection algorithm to identify the heated tube edges and subsequently identify the centreline of the tube. Surface temperatures are extracted along this line at each pixel, resulting in a temperature measurement approximately every $300 \mu \mathrm{m}$. This step is repeated for each image resulting in a temperature contour map, presented in Fig. 4(c). Plotted on the $x$-axis is the distance along the tube from the inlet while the $y$-axis represents each image number in recorded sequence, i.e. representative of the time domain and quantified through the recording frequency. The colour contour map represents the tube wall temperature in degrees Celsius with magnitude indicated by the legend shown. The code allows the user to select the range of images from which the average is calculated, and the output is the mean temperature along the tube surface, shown in Fig. 4(d). The upper and lower lines represent three standard deviations of periodically fluctuating temperature along the length of the tube. It is important to note, these fluctuations do not represent an error, rather, they highlight the unsteady nature of the heat transfer processes associated with such a flow regime.
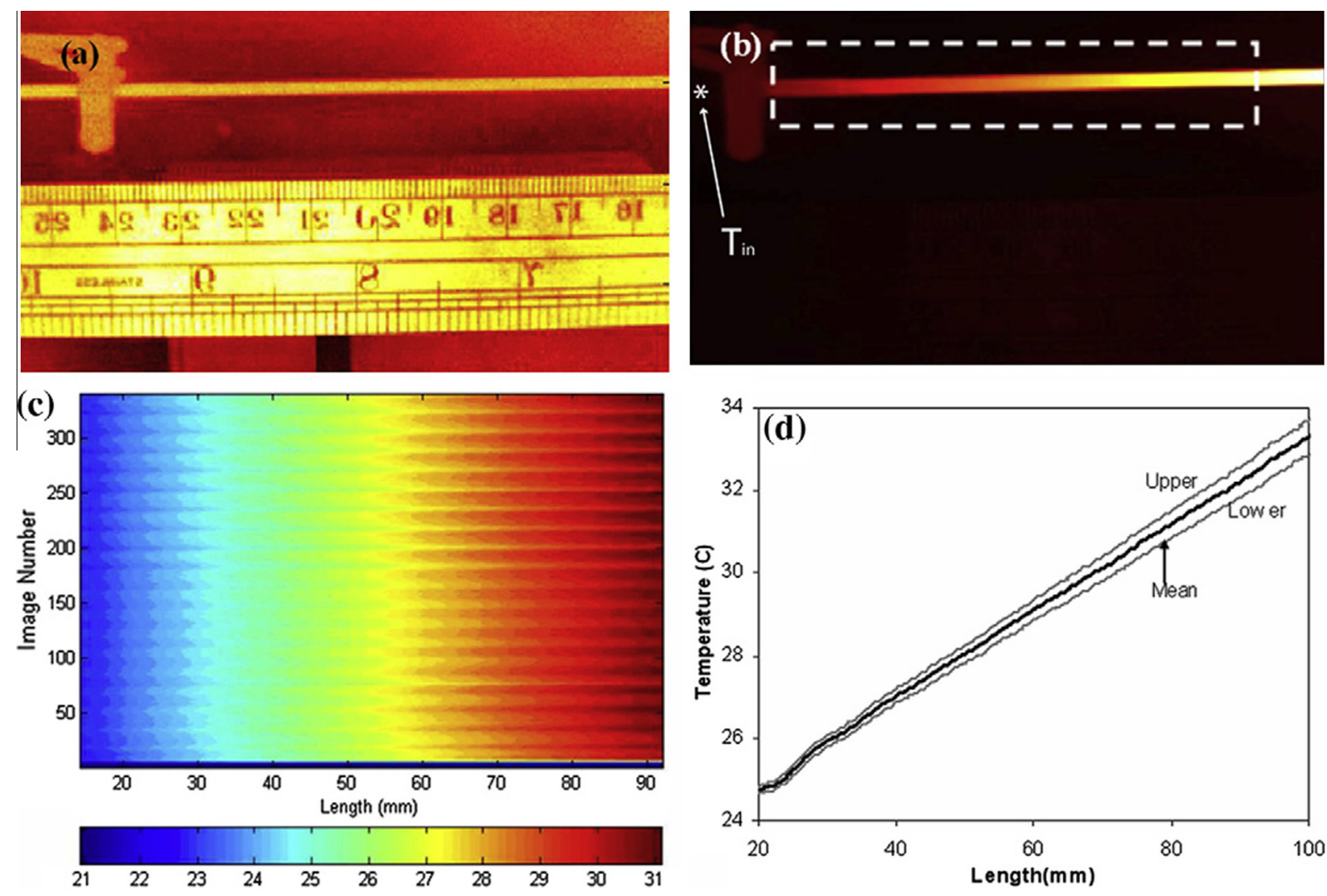

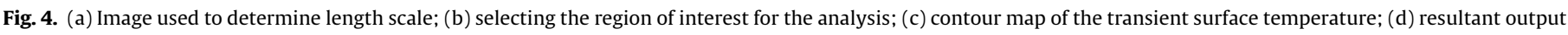
of analysis, profiles of mean, upper and lower surface temperatures. 


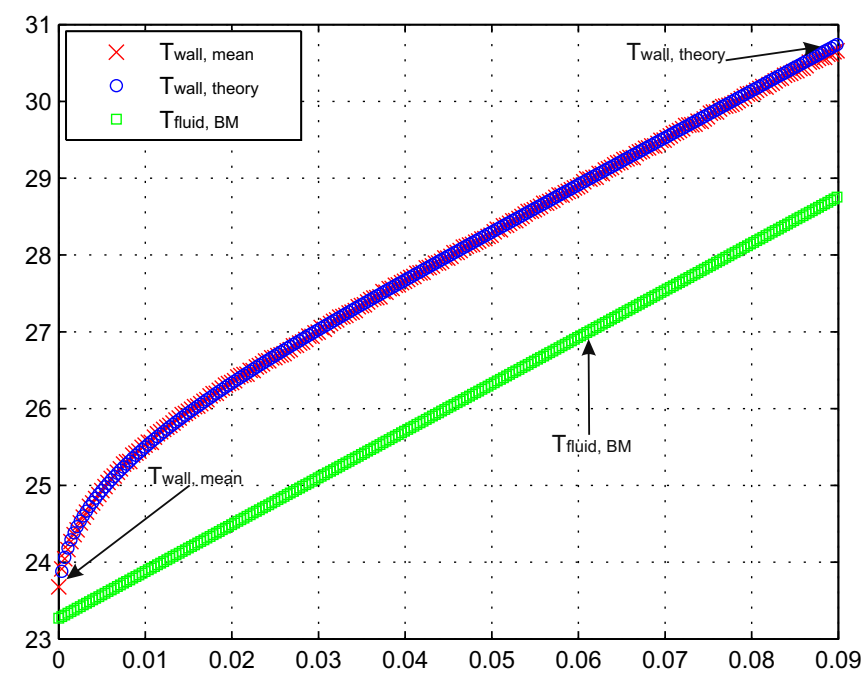

Fig. 5. Single phase temperature profiles, used as verification of the experimental facility and heat flux calibration.

\subsection{System calibration}

The experimental facility was calibrated using single phase flow theory. Good agreement was found for five different flow rates spanning over three orders of magnitude of inverse Graetz number, $x^{*}$. Fig. 5 presents a comparison of the experimental data points with theory and highlights the accuracy of the experimental facility. This particular plot represents a Reynolds number, Re, of approximately 175.6 and a constant heat flux of approximately $5000 \mathrm{~W} / \mathrm{m}^{2}$. The mean wall temperatures closely follow those calculated theoretically, using the expressions presented in Eqs. (1) and (3) where the local temperatures were calculated using the temperature difference between the wall and bulk mean and are based on the local Nusselt number. As a constant wall heat flux was applied to the flow, the local bulk mean temperature increases linearly from $T_{i n}$ and was calculated using an energy balance between the heat added and the enthalpy of the fluid. The inlet temperature was also inferred from the infrared images, immediately upstream of the thermal entrance point; this is highlighted in Fig. 4(b). Calibration also enabled the electrical resistance of the stainless steel tubing, and hence the heat flux values, to be verified.

\subsection{Uncertainty analysis}

The uncertainties in the measurement of temperature, flow rate, length, tube diameter and supplied heat flux were estimated to be: $\pm 0.1 \mathrm{~K}, \pm 0.5 \%, \pm 100 \mu \mathrm{m}, \pm 50 \mu \mathrm{m}$ and $\pm 0.5 \%$ respectively. Using these values, the uncertainties in inverse Graetz number, $x^{*}$, and local Nusselt number, $N u_{x}$, were calculated using the method of Kline and McClintock [34] to be: $x^{*}: 3.39-8.43 \%$ and $N u_{x}: 4.44-10.13 \%$. Using an energy balance technique put forward by Stafford et al. [35], the effects of secondary heat transfer mechanisms, such as natural convection, radiation and axial conduction, were quantified. The total heat losses in the system, due to these secondary heat transfer mechanisms, were found to be less than $3 \%$ and could therefore be neglected.

\section{Results and discussion}

This section presents and analyses the results obtained from this investigation into liquid-liquid Taylor flows. The flows were subject to a constant wall heat flux boundary condition using the experimental test facility presented in the previous section. The results are drawn from time averaged wall temperature profiles generated over the thermally developing and developed regions of the experimental test section and are discussed in two separate sub-sections. The discussion first examines the heat transfer enhancements attainable in a dimensioned format and then generalises these results by presenting them in dimensionless format. The identified characteristics are then used to develop a model to predict the thermal behaviour of a liquid-liquid flow regime subject to a constant wall heat flux boundary condition.

\subsection{Thermal characteristics}

Fig. 6 presents a dimensioned plot of the tube wall temperature profile, $T_{w}-T_{B M}$, as a function of the distance from the entrance of the heated test section, $x$. Included in the plot are three experimental results for a Dodecane/water flow where the dimensionless carrier, $L_{C}^{*}$, and dispersed, $L_{D}^{*}$, slug lengths vary from 0.69-6.26 and $1.66-3.75$, respectively. Single phase tube wall temperatures are plotted as a reference, and these were calculated using Eqs. (1) and (3). The plot highlights two key features: (1) the addition of a second immiscible phase to create a segmented flow regime results in a marked reduction in the time-averaged tube wall temperature profile compared with that offered by an equivalent Poiseuille flow regime; and (2) reduction in $L_{C}^{*}$ and increases in $L_{D}^{*}$ result in appreciable reductions in the tube wall temperature. Taking a closer look at the Dodecane/water temperature profiles, and specifically at $L_{C}^{*}=6.26$, the temperature difference initially increases with axial distance, $x$, and peaks at $0.01 \mathrm{~m}$ downstream from the thermal entrance point. After this point, the temperature difference oscillates towards a constant value, at approximately $0.042 \mathrm{~m}$. Howard et al. [26] stated that these oscillations were a transient effect due to the alternating slug flow structure. The constant temperature difference is maintained for a period before it begins to decrease again with increasing $x$. The temperature profiles of the other data sets presented in Fig. 6 differ from that of $L_{C}^{*}=6.26$. The flows tend towards a constant temperature difference rather than oscillate towards such a condition. However, similar to the case of $L_{C}^{*}=6.26$, after maintaining a constant temperature difference for a period, the temperature difference also begins to diminish with increasing $x$. A noteworthy feature of Fig. 6 is that these regions of constant temperature difference occur closer to the thermal entrance point as $L_{C}^{*}$ decreases and $L_{D}^{*}$ increases, highlighting the shorter thermal entrance length of slug flows compared with continuous flow.

The most appropriate way of analysing and presenting data of this nature is in dimensionless form, as shown in Fig. 7. The experimental temperature differences plotted in Fig. 6 are replotted in the form of the local Nusselt number, $N u_{x}$, while the axial distance from the thermal entrance point is replotted as the inverse Graetz number, $x^{*}$. The dimensionless position was calculated based on the inlet $R e$ and the mean two phase velocity, $U_{m}$, and local Nusselt numbers were calculated using the thermophysical properties of the carrier phase, as this is the phase that wets the heated tube walls. A notable feature of Fig. 7 is that, irrespective of $L^{*}$, the presence of a Taylor flow regime results in substantial enhancements in $N u_{x}$ over Poiseuille flow in both the thermal entrance and fullydeveloped regions. The improved performance in the entrance region would be of particular importance in applications where the heat exchanger length is of the order of the thermal entrance length. Enhancements up to $600 \%$ over conventional Poiseuille flow were observed in the fully-developed region. Similar enhancements were reported by Howard et al. [26] and Walsh et al. [36] for liquidgas flows, however, only after the results were normalised by the percentage contact area of the cooling fluid. When presented as a direct comparison however, the authors documented enhance- 


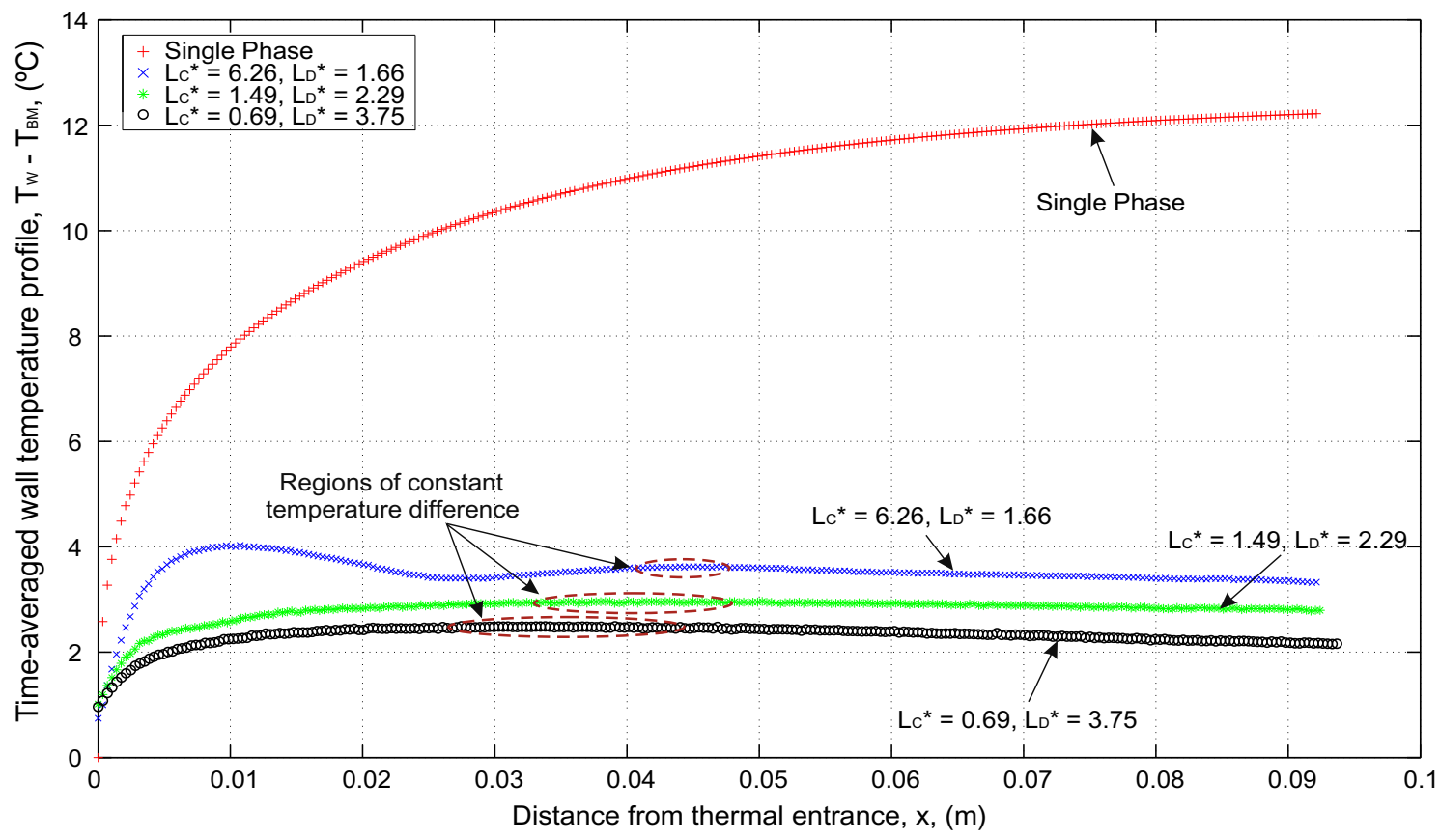

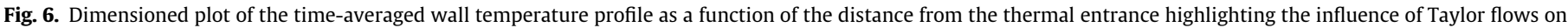
the local surface temperatures. The flow has a constant Re and input heat flux of 46.1 and $5000 \mathrm{~W} / \mathrm{m}^{2}$ respectively.

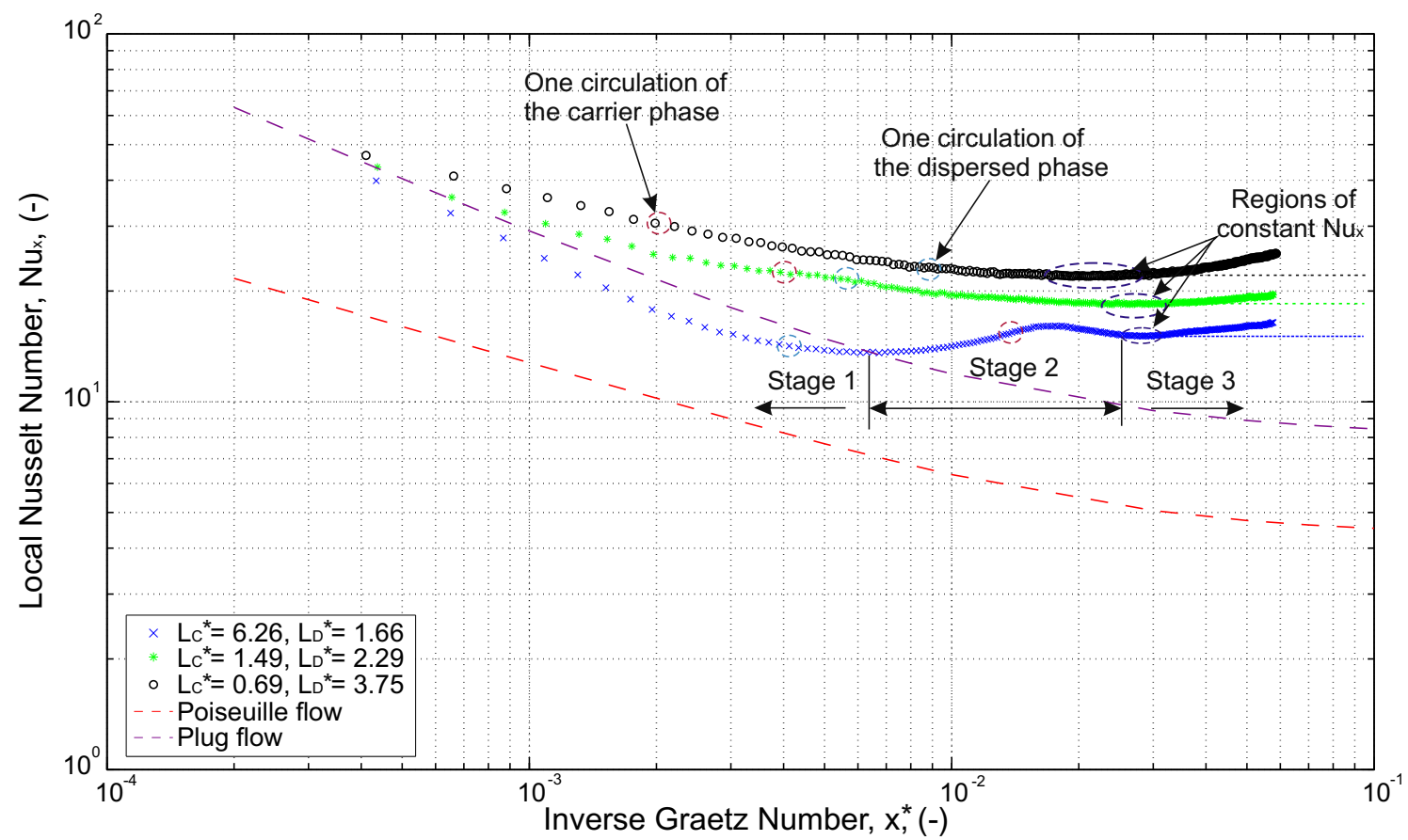

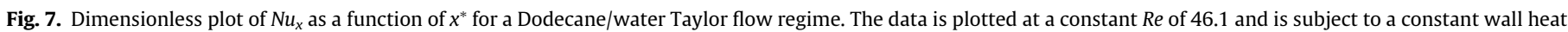
flux of approximately $5000 \mathrm{~W} / \mathrm{m}^{2}$. Included in the plot are the theoretical Poiseuille and plug flow limits.

ments up to $200 \%$. Similar enhancements over single phase flow were reported by [15,21,37]. Fig. 7 also highlights the effects of slug length on $\mathrm{Nu}$, as it is evident that reductions in $L_{C}^{*}$ and increases in $L_{D}^{*}$ result in improved thermal performance, with the fully-developed $N u_{x}$ increasing from approximately 15 to 22 , and similar observations were reported by Horvath et al. [38] and Oliver and Young [22]. Consequently, shorter carrier slugs and longer water slugs should be preferred in order provide the greatest heat transfer enhancement. It is also worth noting that slugs have a shorter ther- mal entrance length compared with continuous flow. This feature, which was also reported by [1,37] and [24], has been attributed to the increased mixing within the fluid segments resulting in the flow reaching thermal equilibrium faster. Consequently, the flow reaches a fully-developed state earlier in the channel.

Examining heat transfer rates in slug flows, Che et al. [16] identified three stages of thermal boundary layer development. These stages are highlighted in Fig. 7 and are superimposed on the $L_{C}^{*}=6.26$ result. In stage 1 , the thermal boundary layer is initially 
thin, which results in a small temperature difference between the wall and the flow, $T_{W}-T_{B M}$, and a large $N u_{x}$. However, as the boundary layer develops, $N u_{x}$ decreases and $T_{W}-T_{B M}$ increases, see Fig. 6 , with increasing $x^{*}$. At stage 2 , due to the presence of the hemispherical caps, fresh fluid is advected within the slugs resulting in a renewal of the thermal boundary layer. Thus, $T_{W}-T_{B M}$ decreases and $N u_{x}$ increases. This recirculation of flow within the slugs has been shown by Muzychka et al. [39] to be the primary mechanism responsible for the enhanced heat transfer rates seen in Taylor flows. This increase in $N u_{x}$ occurs until the heated fluid comes into contact with the heated tube wall again and corresponds with the peak in $N u_{x}$. According to Walsh et al. [36], this peak should correspond to one circulation length of the slug, which equates to twice the slug length plus the tube diameter. Circulation lengths for both the carrier and dispersed slugs are highlighted by pink and blue circles in Fig. 7. Following this, a similar pattern in $\mathrm{Nu}_{x}$ occurs in the downstream direction, however its magnitude is significantly damped and a constant temperature difference, $T_{W}-T_{B M}$, is approached. In this final stage, stage 3 , a constant temperature difference exists between the wall and the flow stream and the flow is said to be fully-developed thermally, resulting in a constant $N u_{x}$. It is also evident from Fig. 7 that the $N u_{x}$ profiles of the other Dodecane/water flows do not follow the same trend as that of $L_{C}^{*}=6.26$. Similar $N u_{x}$ profiles were observed in the works of Howard et al. [26] and Walsh et al. [36] for flows with $L_{C}^{*} \approx 1$. The authors observed that in the thermal entrance region, the flows had heat transfer characteristics similar to that of plug flow. Howard et al. [26] proposed that the enhancements in $N u_{x}$ above the plug flow limit were due to a form of impingement at the leading edge of the slug where contact is made between the fluid and the wall. Due to the small volume of fluid in the slug, the flows quickly approach a fully-developed state and no peak in $N u_{x}$ is observed in the data. It is thought that this constant $N u_{x}$ is a result of the continuous phase reaching a thermally fully-developed state. However, similar to the case where $L_{C}^{*}=6.26$, after this thermally fully-developed state is reached, $N u_{x}$ begins to increase with increasing $x^{*}$.

It is postulated that these increases in $N u_{x}$, after steady state is achieved, are the result of dispersed phase effects. In a liquid-gas flow regime, the dispersed gaseous phase makes a negligible contribution thermally to the overall flow. However, in a liquid-liquid flow regime the dispersed phase can make a significant contribution thermally, depending on its thermophysical properties. Water was used as the dispersed phase in all experiments in the current study and has a density, $\rho$, and specific heat capacity, $c_{p}$, of approximately $920 \mathrm{~kg} / \mathrm{m}^{3}$ and $4.2 \mathrm{~kJ} / \mathrm{kg} \mathrm{K}$, respectively, thus it has a larger thermal capacitance compared with air, $\rho \approx 1.2 \mathrm{~kg} / \mathrm{m}^{3}$ and $c_{p}$ $\approx 1 \mathrm{~kJ} / \mathrm{kg} \mathrm{K}$. Separating the dispersed slugs from the heated tube wall is a thin film of the carrier phase, illustrated in Fig. 1. Due to its low thermal conductivity, $k \approx 0.1 \mathrm{~W} / \mathrm{m} \mathrm{K}$, the carrier phase acts as an insulator or thermal barrier between the dispersed slugs and the heated wall, thus limiting the role the dispersed phase plays in the removal of heat. The liquid film thickness, $\delta$, in Fig. 6 was calculated using Eq. (5), which was developed by the current authors, [31], in a previous work examining the thickness of the liquid film in liquid-liquid flows:

$\frac{\delta}{R}=0.35(C a)^{0.35}(W e)^{0.10}$

The film thickness was found to equal $15.7 \mu \mathrm{m}$ or, relative to the tube radius, $2.1 \%$. Due to the high levels of shear at the interface between the liquids, there is a non-negligible flow within the liquid film which results in heat being convected away from the tube walls. However, there is also a no slip boundary condition at the interface between the liquid phases and consequently, heat is conducted into the dispersed slugs. Due to the recirculation of flow within the dispersed slug - similar to that in the continuous phase - the heat is continuously removed from the film resulting in the reduction in $T_{W}-T_{B M}$ seen in Fig. 6 . As in the carrier phase, this would continue until the dispersed slug reaches thermal equilibrium. Examining the potential film effects further, Fig. 8 is a plot of $N u_{x}$ as a function of $x^{*}$ for a Dodecane/water combination flowing at an $R e=92.1$ and $C a=0.003$. A thicker liquid film now separates the dispersed slugs from the heated tube walls compared to Fig. 7. The thickness of the film was calculated using Eq. (5) and found to be approximately $40 \mu \mathrm{m}$, or $5 \%$ of the tube relative to the radius. It can clearly be seen in Fig. 8 that the different Dodecane/water flows reach a constant $N u_{x}$ and, similar to Fig. 7, do not maintain this constant $N u_{x}$, but rather increase with $x^{*}$. To highlight the increase in $N u_{x}$, fully-developed asymptotes are included in the plot. However, unlike the data plotted in Fig. 7, the disparity between the fully-developed asymptotes and the experimental data is greatly diminished. The film separating the dispersed slugs from the heated tube wall in Fig. 8 is approximately twice as thick as that in Fig. 7. Consequently, the film provides an even greater thermal barrier between the dispersed slugs and the heated tube wall, thus restricting the involvement of the dispersed phase in the removal of heat. This trend continues as film thickness increases, where Fig. 9 is a dimensionless plot of $N u_{x}$ as a function of $x^{*}$ for a Pd5/water Taylor flow. The more viscous Pd5, (see Table 1), deposits a thicker film on the tube wall. Liquid film thicknesses were calculated using Eq. (5) and found to equal $53 \mu \mathrm{m}$, or $7 \%$ relative to the tube radius. It is clear in Fig. 8 that the flows deviate from the fully-developed asymptotes, however, the deviations, with increasing $x^{*}$, are practically negligible. It is clear therefore, that increases in film thickness limit the role of the dispersed phase in the removal of heat.

A noteworthy feature of Figs. 7 and 8 is that for carrier slugs of approximately equal length, $L_{C}^{*} \approx 0.65$, an increase in film thickness of $16.3 \mu \mathrm{m}$, or $2.1 \%$, corresponds to a reduction in $N u_{x}$ from approximately 23 to 19 . In an exploratory investigation, Talimi et al. [40] examined the influence of film thickness on the heat transfer in liquid-gas Taylor flows. The authors noted that as the film increased in thickness, the Nusselt number decreased. This reduction in $N u_{x}$ was attributed to the increase in flow bypass through the liquid film which results in a reduction of the recirculation of flow in the continuous phase. Consequently, the flow becomes more akin to Poiseuille flow and $N u_{x}$ decreases. Similarly, as the film increases in thickness to approximately $7 \%$ of the channel, Fig. 8, the oscillations seen in the $N u_{x}$ profiles, Figs. 6 and 7, are dampened out. Similar observations were documented by Howard et al. [26] and were attributed to the increase in flow bypass through the liquid film.

\subsection{Heat transfer correlation}

Although a number of experimental and numerical works have been undertaken examining the heat transfer enhancements associated with Taylor flows - [16,21,22,25] - few have proposed correlations to model the thermal behaviour. Of the works that have, the majority have proposed correlations for liquid-gas flows subject to an isoflux boundary condition $[38,41,42]$. Thermal management applications typically subject flows to a constant wall heat flux boundary condition. However, relatively little work has been done on two phase flows in this area, with only the work of Walsh et al. [36] resulting in a correlation to model their behaviour. However this model was developed for a water-air flow regime only, and, as a result, is not applicable to the present study. To the best of the authors' knowledge, there are, at present, no correlations pertaining to liquid-liquid Taylor flows subject to a constant wall heat flux boundary condition. This work aims to address this gap in the literature. 


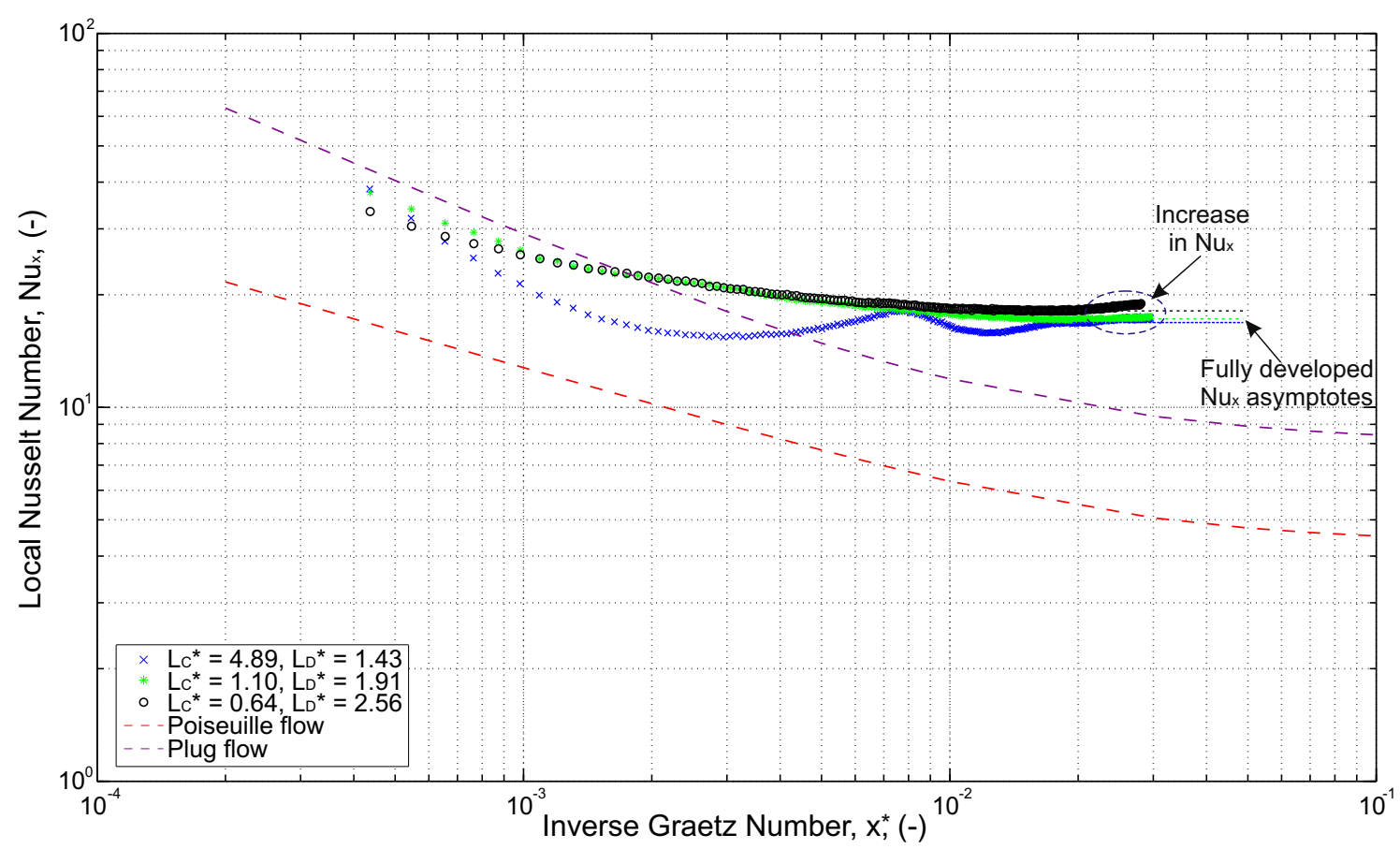

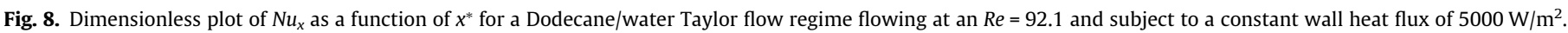
The plot highlights the effects of liquid film thickness, $\delta$, on $N u_{x}$, where relative to the tube radius; the film occupies $4.2 \%$ of the tube.

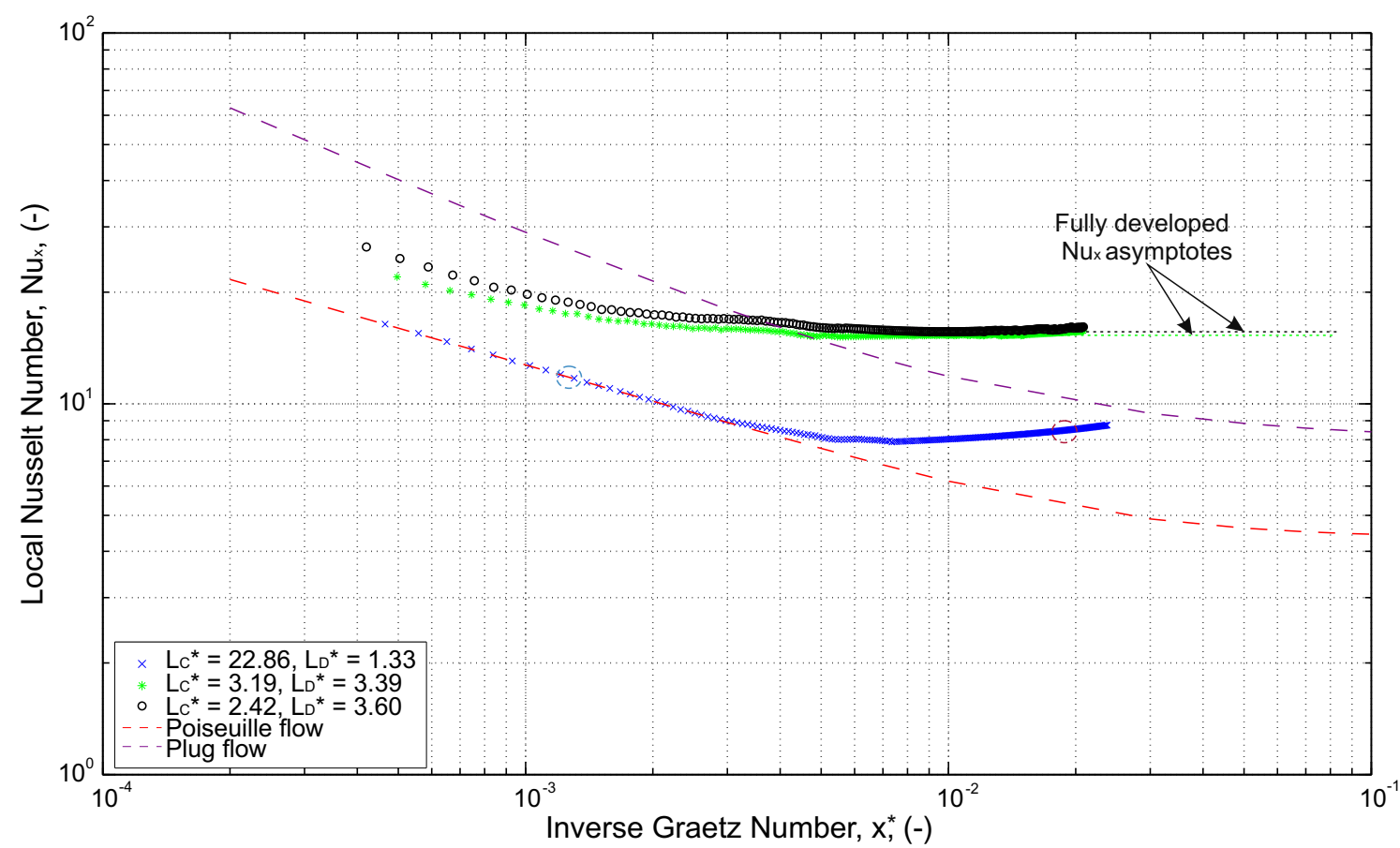

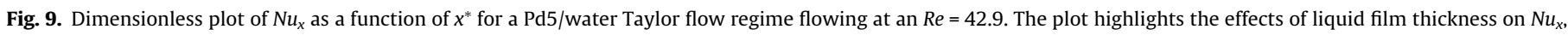
where, relative to the tube radius the film occupies approximately $7 \%$ of the tube.

The thermal characteristics of three different liquid-liquid combinations were examined. By isolating specific experimental parameters, such as slug length, it allows for a direct comparison in $N u_{x}$ for the different liquid-liquid combinations. Fig. 10 is a dimensionless plot of $N u_{x}$ as a function of $x^{*}$ for a constant $L_{C}^{*} \approx 1.4$. The experimental data presented in Fig. 10 has the following ranges in $R e, 3.2-46.1$, void fraction, $\varepsilon=Q_{D} / Q_{T}, 0.42-0.70$, and Prandtl number, $P r, 23.6-265.4$. Included in the plot, for compara- tive purposes, are the theoretical Poiseuille and plug flow limits. It is evident from Fig. 10 that the differences in $N u_{x}$ in the thermally fully-developed region between the different liquid-liquid combinations are minimal, for changes in the carrier phase, with 13.518.5. However, significant differences are observed in the transition from thermally developing to thermally fully-developed. Few works have examined the effects of varying the carrier fluid on the thermal performance of Taylor flows. Of these Urbant 


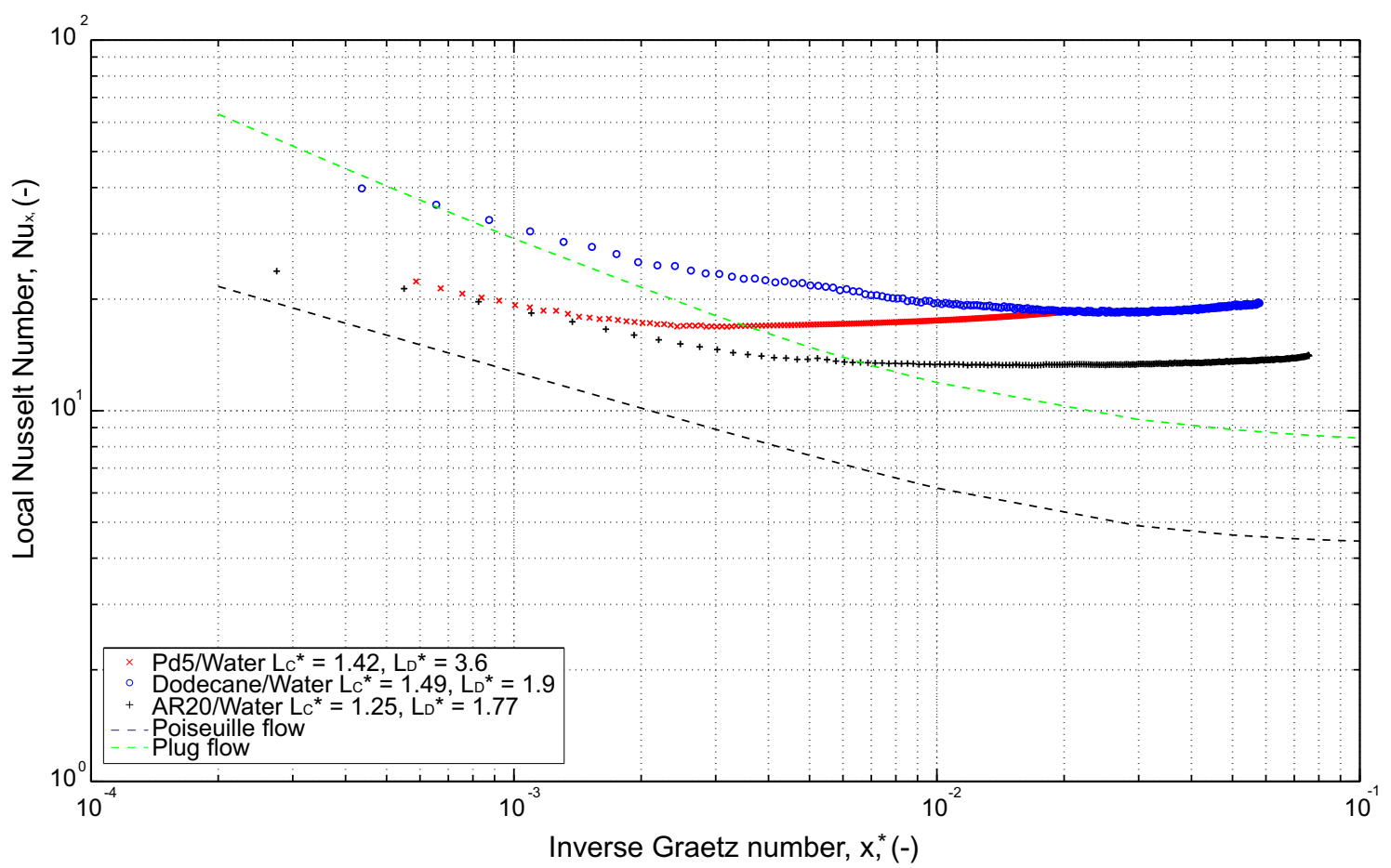

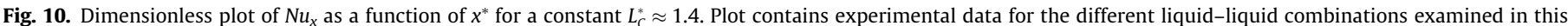
work over the following range in $\operatorname{Re}, 3.2-46.1, \varepsilon, 0.42-0.7$, and $\operatorname{Pr}, 23.6-265.4$.

et al. [43] varied the carrier phase to validate a single phase numerical model, and Hughmark [44] examined the effects in turbulent liquid-gas flows, which is beyond the scope of this paper. Varying the carrier phase, Howard et al. [26] noted that variations in $\mathrm{Pr}$ resulted in notable changes to the transition from thermally developing to fully-developed. However, once the data had been normalised using the correct void fraction, excellent agreement was observed between the different liquid-gas flows in the fully-developed region. The authors make no specific comment in relation to this agreement. In a single phase flow regime, irrespective of the fluid, and hence $P r$, flowing in the capillary, a constant $N u$ is obtained once the flow reaches a thermally fully-developed state. In a two-phase flow regime, a similar phenomenon should occur; the flow should tend towards a constant $\mathrm{Nu}$ when both phases are fully-developed thermally. Consequently, any variations in the fully-developed $N u_{x}$ should be the result of changes in slug length, as highlighted in Section 4.1. Additionally, a change in $\mathrm{Pr}$ between the fluids is accounted for in the inverse Gratez number, $x^{*}$, in Eq. (2).

Fig. 11 examines the influence of the carrier slug length on the fully-developed $N u_{x}$. Plotted on the ordinate is the enhancement in

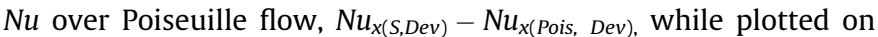
the abscissa is the dimensionless carrier slug length, $L_{C}^{*}$ Experiments were carried out over a wide range in $L_{C}^{*}$, presented in Table 2, in order to obtain an accurate approximation of the dependence of $N u_{x}$ on $L_{C}^{*}$. In flows where $L_{C}^{*} \geqslant 10$, the flow had yet to reach its fully-developed limit within the experimental test section. Consequently, values of $N u_{x(S, D e v)}$ were chosen at a distance equal to one circulation length from the thermal entrance point. This location was chosen as, according to [36], the flow reaches its steady state $\mathrm{Nu}$ at once circulation length and oscillates about this value thereafter. Both $[26,40]$ found that the film that separates the dispersed slugs from the wall has an effect on $N u_{x}$. However, [40] stated that this effect dissipated as the flow moved downstream and reached a fully-developed state. It was also noted in Section 4.1, that in flows where the film occupied a small frac-

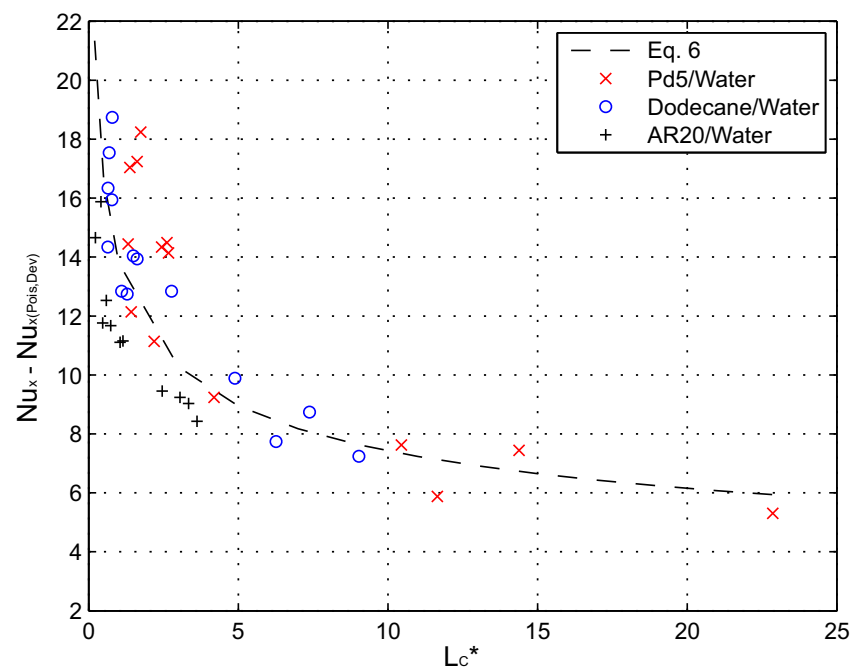

Fig. 11. Plot of the increase in the fully-developed $N u_{x}$ above the theoretical single phase limit as a function of dimensionless carrier slug length.

tion of the channel, $\delta / R<5 \%$, the superior thermal properties of the dispersed water phase resulted in an additional temperature reduction at the wall. However, the $N u_{x}$ values plotted in Fig. 11 are the steady state $N u_{x}$ achieved prior to the dispersed phase effects being felt at the wall, as highlighted in Fig. 7.

The plot clearly highlights the effects of $L_{C}^{*}$ on the enhancement in $N u_{x(S, D e v)}$ over Poiseuille flow, particularly at values of $L_{C}^{*}<3$. Included in the plot is a best fit line of the data, which follows a power law trend. The fully-developed asymptotic limit for a liquid-liquid Taylor flow regime is given by Eq. (6), where the experimental data points presented in Fig. 11 fall within $+15 \%$ of the correlation. The disagreement between the experimental data 


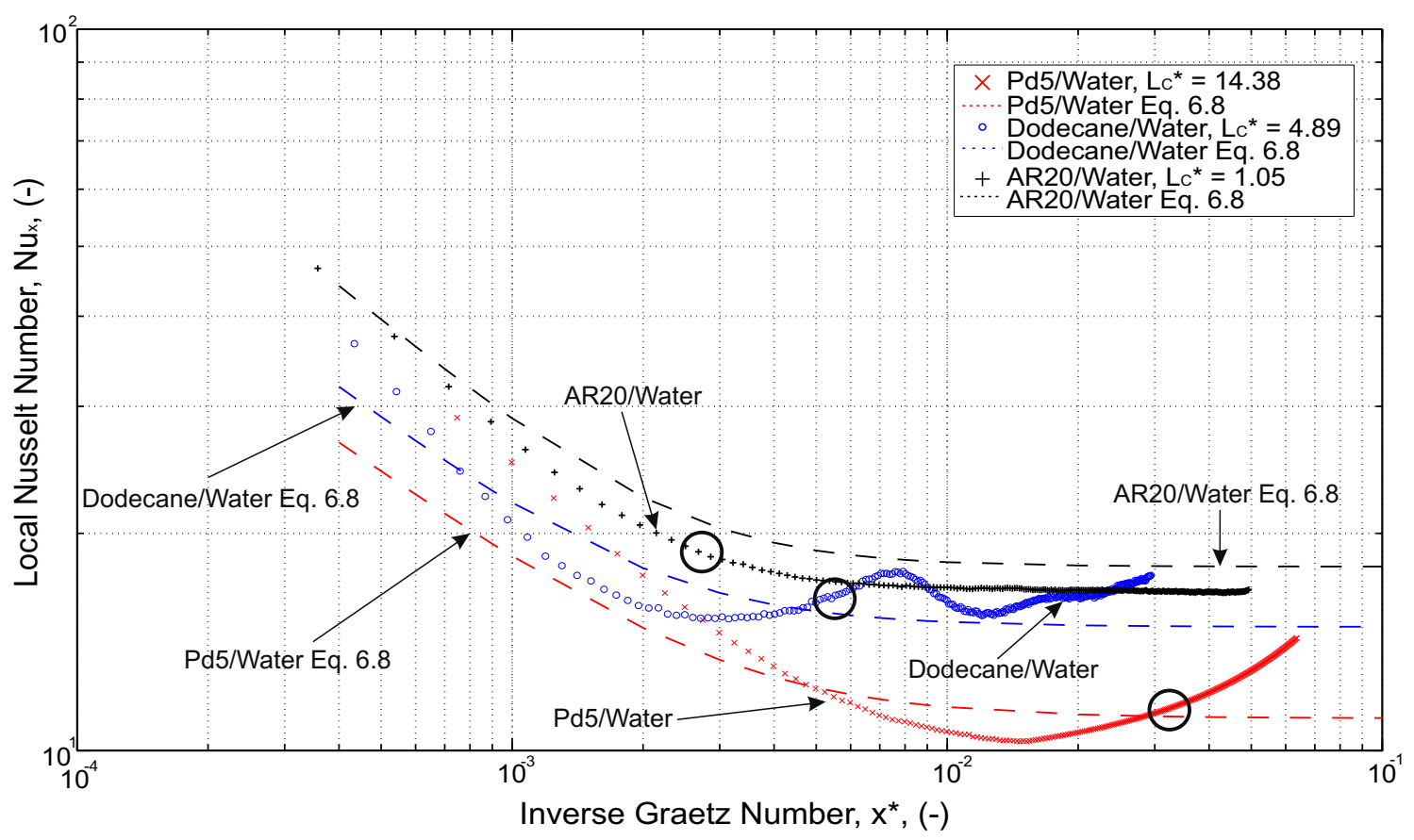

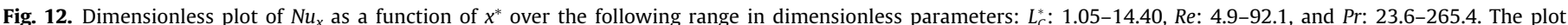

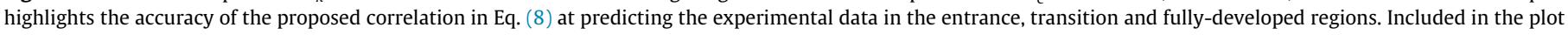
are indicators marking one circulation length.

and the correlation is most prominent in carrier slugs approaching the channel diameter, $L_{C}^{*} \approx 1$ :

$N u_{x(\text { S,Dev })}=4.36+13.7\left(L_{C}^{*}\right)^{-0.23}$

Focusing on the thermal entrance region, Walsh et al. [36] found that $N u_{x}$ varied between the Poiseuille and plug flow limits. Similar to the fully-developed state, $N u_{x}$ was found to vary inversely with $L_{C}^{*}$ in the thermal entrance region. Experimental results in Figs. 7-9 show that $N u_{x}$ varies between the Poiseuille and plug flow limits as $L_{C}^{*}$ varies. Similar to the correlation proposed by [36], this behaviour was found to be best correlated using a weighted mean approach between these two limits and is presented in Eq. (7). Slugs of infinite length should fall on the Poiseuille flow limit, while slugs of order the channel diameter should fall on the plug flow limit. Local $\mathrm{Nu}$ will vary linearly between these limits at intermediate carrier slug lengths:

$N u_{x(S, E n t)}=N u_{x(\text { Pois,Ent })}+\left(\left(N u_{x(\text { Plug }, E n t)}-N u_{x(\text { Pois,Ent })}\right)\left(L_{C}^{*}\right)^{-0.4}\right)$

These expressions, for the thermal entrance and fully-developed regions, represent the asymptotic limits of the flow. Using the blending approach of Churchill and Usagi [45], these limits are combined in Eq. (8) to form a new correlation to model the thermal behaviour of liquid-liquid Taylor flows subject to a constant wall heat flux boundary condition:

$N u_{x(S)}=\left(\left(N u_{x(S, E n t)}\right)^{4}+\left(N u_{x(S, D e v)}\right)^{4}\right)^{\frac{1}{4}}$

The accuracy of this correlation is graphically illustrated in Fig. 12, where experimental measurements are compared with the predictions of $N u_{x}$ from Eq. (8) over a wide range of experimental parameters. Dimensionless carrier slug length, 1.05-14.38, Re, 4.92-92.12, and $\operatorname{Pr}, 23.6-265.4$, span several orders of magnitude for three different liquid-liquid combinations. Included in the plot are circles that indicate one full circulation of the carrier phase. It can be seen in Fig. 12 that the model provides excellent agreement with the experimental data in the thermally developing region for short and intermediate slug lengths, $L_{C}^{*}<5$. At $L_{C}^{*}=14.38$ there are significant deviations in the early thermal entrance region, $\pm 30 \%$, however, this deviation diminishes as $x^{*}$ increases and the flow begins to transition towards fully-developed. Similarly, the correlation provides an excellent approximation of the transition from thermally developing to fully-developed in the short and intermediate slug lengths. There is a renewal of thermal boundary layer in the Dodecane/water flow, which the correlation does not account for. Nonetheless, the correlation still approximates $N u_{x}$ to within $+10 \%$. The correlation is also in accordance with the steady state values proposed to occur at one circulation length of the carrier phase, with the correlation predictions within $+10 \%$ of the experimental measurements. Overall, the correlation presented in Eq. (8) provides a novel means of predicting the $N u_{x}$ in liquid-liquid Taylor flows subject to a constant wall heat flux boundary condition.

Although Taylor flow regimes induce significant heat transfer enhancements over single phase flows, it is worth noting that the addition of a second immiscible phase results in a significant increase in the pressure drop relative to the single phase flow case. Pressure drop now becomes a key design parameter as it affects flow rates, stability, sizing of the pumps and hence the overall cost of the system. In recent works by the authors examining the influence of carrier and dispersed slug length on the pressure drop induced by liquid-liquid and liquid-gas Taylor flows, a novel model was presented which addressed the effects of slug length on pressure drop, [46]. The present model, used in conjunction with the aforementioned pressure drop model, would allow for concise design and analysis of Taylor flow systems for a wide variety of applications.

\section{Conclusions}

The paper presents novel experimental insights into the thermal characteristics of liquid-liquid Taylor flows subject to a constant heat flux boundary condition. A high resolution IR thermography system was used to acquire surface temperature 
measurements of the heated channel walls in both developing and fully-developed regions. In total, three oil/water combinations were examined as part of this study; with the effects of slug length and carrier phase variations on the thermal characteristics documented.

The addition of a second immiscible liquid phase resulted in heat transfer enhancements throughout the experimental test section, with enhancements up to $600 \%$ over Poiseuille flow noted. Slug length and film thickness changes were found to have a significant effect on the heat transfer rates, with reductions in carrier slug length and increases in dispersed slug length resulting in marked increases in Nusselt number. Increases in film thickness were found to reduce the Nusselt number. It was observed in the experimental data that in flows where $\delta / R<5 \%$, the dispersed phase played a greater role in the removal of heat and further enhancements in the local Nusselt number were observed. However, in flows where $\delta / R>5 \%$, the film acted as a thermal barrier between the dispersed slugs and the heated walls and the effects of the dispersed slug in the removal of heat was diminished. Oscillations were observed in the Nusselt number profiles of the lower Capillary number flows. These oscillations, the result of the recirculation of flow within the liquid slugs, were dampened out as Capillary number, and hence film thickness, increased.

A novel correlation was developed to model the thermal behaviour of liquid-liquid Taylor flows. The correlation consists of separate expressions, for the thermal entrance and fully-developed regions, blended together. Excellent agreement was observed between the model and experimental data over the range $L_{C}^{*}<5$, with the correlation modelling the experimental data to within $+10 \%$. However, deviations up to $+30 \%$ were observed in the thermal entrance region in flows where $L_{C}^{*}>14$.

Overall, the findings reported in this paper provide a greater insight into the parameters that influence the heat transfer rates in liquid-liquid Taylor flows subject to a constant heat flux boundary condition.

\section{Conflict of interest}

None declared.

\section{Acknowledgments}

The authors gratefully acknowledge the financial support of the Irish Research Council through the Embark Initiative. The involvement of Jeff Punch is supported by Science Foundation Ireland under Grant No. 10/CE/I1853.

\section{References}

[1] A. Asthana, I. Zinovik, C. Weinmueller, D. Poulikakos, Significant Nusselt number increase in microchannels with a segmented flow of two immiscible liquids: an experimental study, Int. J. Heat Mass Transfer 54 (2011) 1456-1464.

[2] V. Egan, J. Stafford, P.A. Walsh, E.J. Walsh, An experimental study on the design of miniature heat sinks for forced convection air cooling, ASME J. Heat Transfer 131 (7) (2009) 071402.

[3] E.J. Walsh, P.A. Walsh, R. Grimes, V. Egan, Thermal management of low profile electronic equipment using radial fins and heat sinks, ASME J. Heat Transfer 130 (12) (2008) 125001.

[4] N. Jeffers, J. Punch, E.J. Walsh, An experimental characterisation of miniature scale cold plates for electronics cooling applications, in: ASME-JSME Thermal Engineering Summer Heat Transfer Conference, Vancouver, British Columbia, Canada, 2007.

[5] N. Jeffers, J. Punch, E.J. Walsh, M. Mc Lean, Heat transfer from novel target surface structures to a normally impinging, submerged and confined water jet, J. Therm. Sci. Eng. Appl. 1 (3) (2009) 031001.

[6] S.J.M. Fabbri, V.K. Dhir, A comparative study of cooling of high power density electronics using sprays and microjets, J. Heat Transfer 127 (2005) 38-48.

[7] E. Rahim, A. Bar-Cohen, I.A. Ali, Two-phase microgap cooling of a thermallysimulated microprocessor chip, in: 13th IEEE ITherm Conference, San Diego, CA, USA, 2012.
[8] G.L. Morini, Single-phase convective heat transfer in microchannels: a review of experimental results, Int. J. Therm. Sci. 43 (2004) 631-651.

[9] D.B. Tuckerman, R.F.W. Pease, High-performance heat sinking for VLSI, IEEE Electron Device Lett. 2 (5) (1981) 126-129.

[10] T.M. Squires, S.R. Quake, Microfluidics: fluid physics at the nanolitre scale, Rev. Mod. Phys. 77 (2005) 977-1026.

[11] K.B. Anoop, T. Sundararajam, S.K. Das, Effects of particle size on the convective heat transfer in nanofluid in the developing region, Int. J. Heat Mass Transfer 52 (2009) 2189-2195.

[12] R. Zeng, X. Wang, B. Chen, Y. Zhang, J. Niu, X. Wang, H. Di, Heat transfer characteristics of microencapsulated phase change material slurry in laminar flow under constant heat flux, Appl. Energy 86 (2009) 2661-2670.

[13] T. Icoz, Y. Jaluria, Design optimisation of size and geometry of vortex promoter in a two-dimensional channel, J. Heat Transfer 128 (2006) 1081-1092.

[14] N. Janes, Y.S. Muzychka, B. Guy, E.J. Walsh, P.A. Walsh, Heat transfer in gasliquid and liquid-liquid two phase plug flow systems, in: 12th IEEE Intersociety Conference on Thermal and Thermomechanical Phenomena in Electronic Systems, 2010.

[15] A.R. Betz, D. Attinger, Can segmented flow enhance heat transfer in microchannel heat sinks?, Int J. Heat Mass Transfer 53 (2010) 3683-3691.

[16] Z. Che, T. Wong, N.T. Nguyen, Heat transfer in plug flow in cylindrical microcapillaries with constant surface heat flux, Int. J. Therm. Sci. 64 (2013) 204-212.

[17] J.R. Thome, Boiling in microchannels: a review of experiment and theory, Int. J. Heat Fluid Flow 25 (2004) 128-141.

[18] D. Liu, S.V. Garimella, Flow boiling heat transfer in microchannels, J. Heat Transfer 129 (2007) 1321-1332.

[19] T. Harirchian, S.V. Garimella, Boiling heat transfer and flow regimes in microchannels - a comprehensive understanding, J. Electron. Packag. 1 (2011) $1-10$.

[20] J. Jovanovic, E.V. Rebrov, T.A. Nijhuis, M.T. Kreutzer, V. Hessel, J.C. Schouten, Liquid-liquid flow in a capillary microreactor: hydrodynamics, flow patterns and extraction performance, Ind. Eng. Chem. Res. 51 (2012) 1015-1026.

[21] J. Prothero, A.C. Burton, The physics of blood flow in capillaries. 1: The nature of the motion, Biophys. J . 1 (1961) 565-579.

[22] D.R. Oliver, H. Young, Two phase non-Newtonian Flow. Part 2: Heat transfer, Trans. Inst. Chem. Eng. 46 (1968) 106-115.

[23] Y.S. Muzychka, E.J. Walsh, P.A. Walsh, Simple models for thermally developing slug flow in noncircular ducts and channels, in: International Mechanical Engineering Congress and Exhibition, Orlando, FL, USA, 2009.

[24] A. Majumder, B. Mehta, S. Khandekar, Local Nusselt number enhancement during gas-liquid Taylor bubble flow in a square mini-channel: an experimental study, Int. J. Therm. Sci. 66 (2013) 8-18.

[25] Y.S. Lim, S.C.M. Yu, N.T. Nguyen, Flow visualisation and heat transfer characteristics of gas-liquid two-phase flow in microtube under constant heat flux at wall, Int. J. Heat Mass Transfer 56 (2013) 350-359.

[26] J.A. Howard, P.A. Walsh, E.J. Walsh, Prandtl and capillary effects on heat transfer performance within laminar liquid-gas slug flows, Int. J. Heat Mass Transfer 54 (2011) 4752-4761.

[27] L. Graetz, Uber die Waarmeleitungfahigkeit von Flussigkeiten (On the thermal conductivity of liquids) Part 1, Annu. Rev. Phys. Chem. 18 (1883) 79-94.

[28] L. Graetz, Uber die Waarmeleitungfahigkeit von Flussigkeiten (On the thermal conductivity of liquids) Part 2, Annu. Rev. Phys. Chem. 25 (1885) 337-357.

[29] R.K. Shah, A.L. London, Laminar flow forced convection in ducts, Advances in Heat Transfer, Suppl. 1, Academic Press, New York, USA, 1978.

[30] Y.S. Muzychka, M.M. Yovanovich, Forced convection heat transfer in the combined entry region of non-circular ducts, ASME J. Heat Transfer 126 (2004) 54-61.

[31] M. Mac Giolla Eain, V. Egan, J. Punch, Film thickness measurements of liquidliquid slug flow regimes, Int. J. Heat Fluid Flow 44 (2013) 515-523.

[32] M. Mac Giolla Eain, V. Egan, J. Punch, P.A. Walsh, E.J. Walsh, An analysis of the pressure drop associated with liquid-liquid slug flows, in: 11th International Conference on Nanochannels, Microchannels and Minichannels, Sapporo, Japan, 2013.

[33] ASTM, ASTM manual on the use of thermocouples in temperature measurement, 1993.

[34] S.J. Kline, F.A. McClintock, Describing uncertainties in single sample experiments, Mech. Eng. 75 (1953) 385-387.

[35] J. Stafford, E.J. Walsh, V. Egan, Characterising convective heat transfer using infra-red thermography and the heat tin foil technique, Meas. Sci. Technol. 20 (2009) 1-11.

[36] P.A. Walsh, E.J. Walsh, Y.S. Muzychka, Heat transfer model for gas-liquid slug flows under constant heat flux, Int. J. Heat Mass Transfer 53 (2010) 31933201.

[37] B. Mehta, S. Khandekar, Measurement of local heat transfer coefficient during gas-liquid Taylor bubble train flow by infrared thermography, Int. J. Heat Fluid Flow 45 (2014) 41-52.

[38] C. Horvath, B.A. Solomon, J.M. Engasser, Measurement of radial transport in slug flow using enzyme tubes, Ind. Eng. Chem. Fundam. 12 (4) (1973) $431-$ 439.

[39] Y.S. Muzychka, E.J. Walsh, P.A. Walsh, Heat transfer enhancement using laminar gas-liquid slug flow regimes, ASME J. Heat Transfer 133 (2011) 1-9.

[40] V. Talimi, Y.S. Muzychka, S. Kocabiyik, Effects of film thickness on heat transfer in Taylor flow under constant heat flux boundary condition, in: International Mechanical Engineering Congress and Exhibition, Houston, USA, 2012. 
[41] M.T. Kreutzer, J. Peng Du, F. Kaptejin, J.A. Moulijn, Mass transfer characteristics of three-phase monolith reactors, Chem. Eng. Sci. 56 (2001) 6015-6023.

[42] C. Narayanan, D. Lakehal, Two phase convective heat transfer in miniature pipes under normal and microgravity conditions, ASME J. Heat Transfer 126 (2008) 54-61.

[43] P. Urbant, A. Leshansky, Y. Halupovich, On the forced convective heat transport in a droplet laden flow in microchannels, Microfluid Nanofluid 4 (2008) 533542.
[44] G. Hughmark, Holdup and heat transfer in horizontal slug gas-liquid flow, Chem. Eng. Sci. 20 (1965) 1007-1010.

[45] S. Churchill, R. Usagi, A general expression for the correlation of rates of transfer and other phenomenon, AIChE J. 18 (1972) 1121-1128.

[46] M. Mac Giolla Eain, V. Egan, J.A. Howard, P.A. Walsh, E.J. Walsh, J. Punch, Review and extension of pressure drop models applied to Taylor flow regimes. Int. J. Multiphase Flow, in press. 